\title{
Talk, silence and anxiety during one-to-one tutorials: A cross-cultural comparative study of Japan and UK undergraduates' tolerance of silence
}

\author{
$\operatorname{Jim}_{\text {King }}{ }^{(\mathbb{D})} \cdot$ Atsuko Aono $^{2}$
}

Received: 24 January 2017 / Revised: 13 October 2017 / Accepted: 25 October 2017 / Published online: 30 October 2017

(C) The Author(s) 2017. This article is an open access publication

\begin{abstract}
This paper discusses the issue of tolerance of silence within university tutorials from a cross-cultural, comparative perspective. A mixed methods, quasi-experimental approach was employed to measure the length of silence which individual students from samples in Japan and the UK tolerated during a one-to-one staged encounter with their instructor. The comparison groups consisted of two first-year intact classes, one in Japan $(n=20)$ and one in the UK $(n=15)$, both of whom were studying for a Bachelor degree in English. During the tutorial encounter, the instructor refrained from speech from a set point in the meeting. Participants' reactions to the period of silence which ensued were examined in detail using non-verbal coding and their length of silence tolerance was measured precisely. Contrary to the popular notion of the silent 'East' versus the garrulous 'West', the study's quantitative findings revealed there was no significant difference in the length of silence students from both groups could tolerate during tutorials. Furthermore, self-reported feelings of discomfort during the silence were relatively high for both Japanese and UK participants, but length of silence was not found to be correlated with degree of discomfort. Qualitative data were collected from retrospective interviews examining what participants were thinking and feeling whilst the silent encounter was in progress. Testimony illustrating acute feelings of anxiety on the part of both UK and Japanese students was the
\end{abstract}

Jim King

jk249@le.ac.uk

1 Applied Linguistics Section, Department of English, University of Leicester, University Road, Leicester LE1 7RH, UK

2 Department of Psychology, Fukuyama University, Sanzo 1, Gakuen-cho, Fukuyama 729-0292, Japan primary theme to emerge in this phase of data collection. We propose the construct situational silence anxiety to describe such feelings of apprehension during situated encounters in which talk is expected but does not occur.

Keywords Comparative research - Silence in education . Student anxiety · Staff-student interaction · Japan · UK

\section{Introduction}

Although globalisation and the rise of transnational education in recent years has meant that cross-cultural interactions within universities have become an everyday occurrence, difficulties in communication still persist for many students and staff alike when encountering unfamiliar, local discourse practices and turn-taking patterns within new learning situations. Japan's recent push towards the internationalisation of its higher education system (see Hammond 2016; Huang 2014) and the UK's continuing dependence upon the fees generated by international students, coupled to the two societies' very different cultures of learning (Cortazzi and Jin 2013), all mean that Japanese-Anglo staff-student interactions are far from uncommon nowadays and when they do occur, there is the potential for a certain amount of misunderstanding and frustration on the part of participants.

While much useful research has been undertaken into the influence of cultural factors on learners' discussion skills (e.g. Frambach et al. 2014), empirical research into cross-cultural interaction within higher education contexts which puts silence at its very heart is scant to say the least. Research attempting to compare how undergraduates from differing cultural backgrounds react to an enforced period of silence is even rarer still, if non-existent. This means an interdisciplinary approach is necessary in order to look 
beyond the quite narrow choice that education research literature has to offer on silence so that we can better understand the linguistic concepts which lie beneath the intriguing topic of learner tolerance of silence.

\section{Tolerance of silence across cultures}

The issue of cross-cultural differences in the use of silence has received some attention from scholars in the past, most notably within the field of sociolinguistics. A number of writers have suggested that particular cultural groups have been shown to employ culturally specific silence behaviours between and during conversational turns, with some groups favouring relatively longer inter- and intra-turn silent pauses than others (Jaworski 1993; Scollon and Scollon 1981, 1990; Sifianou 1997; Tannen 1984). Although a somewhat simplistic dichotomy which ignores context and overlooks the existence of sub-cultures, 'western' anglophone societies, particularly North American, tend to be characterised as garrulous and intolerant of silence, while 'non-western' and those from the 'East' (e.g. Japan, Korea, China) are thought of as being more reticent and at ease with the absence of talk. In his in-depth exploration of the discourse of silence, Kurzon (1998, p. 23) rightly reminds us though that the 'interpretation of silence must be culture-specific in that each culture tolerates a different length of silence in conversation'. To this we would add that close attention also needs to be paid to the immediate contextual features of any interaction (e.g. the discourse norms of the setting, the interpersonal relationship between interlocutors, the task being undertaken and so on) as context plays a highly significant role in the shaping and the interpretation of an individual's silent behaviour. In the current age of transnational higher education and the cross-cultural interactions which accompany it, educators need to be aware that not all students share the same beliefs about what is an appropriate use of silence during face-to-face interactions.

In their seminal study of dyadic turn-taking, Sacks et al. (1974) found that most transitions between Anglophones engaged in natural conversation involve few or no gaps between turns, and that when silences do occur at socalled Transition Relevance Places (TRPs), this is usually a sign that the interaction is not progressing well. Jefferson (as cited in Watts 1997) claims that inter-turn silences of more than $1.5 \mathrm{~s}$ duration may lead to a perception of disfluency. This compares to Enninger's (1991) investigation of the silences occurring at TRPs in a conversation between three North American Amish adults which saw multiple instances of inter-turn pauses of more than $20 \mathrm{~s}$, with the longest reaching $56 \mathrm{~s}$. Enninger found no evidence that these extended silences led to a breakdown of communication and the participants deemed the conversation to have run smoothly. Yamada (1997) conducted a rare comparative study which sought to examine the length of silent pauses by participants attending Japanese and American business meetings. She found an average of $5.15 \mathrm{~s}$ of silence per minute in the Japanese setting, compared to just $0.74 \mathrm{~s}$ in the American one. The longest silence in the Japanese meeting was $8.5 \mathrm{~s}$, nearly double that of the American one. Yamada suggests that silences were used by Japanese participants to engage in sasshi (empathetic anticipatory guesswork-see Gudykunst and Nishida 1993), allowing them to surmise whether their verbal and implicit messages had been understood and whether they could move on to the next topic.

Yamada's work reflects literature more widely which posits that the Japanese have a natural proclivity for silence in communication and that traditionally within Japanese culture, a greater relative value has been placed on silence in comparison to talk. For example, Clancy (1990) argues that Japanese infants are socialised from an early age into patterns of communication which place emphasis an on implicit, non-vocal understanding and which avoid overly direct verbalisation whenever possible. Hence they are able to perform the role of silent listener well within interactions. McDaniel (2003) suggests that it is the hierarchical nature of Japanese society which ensures subordinates assume a passive, silent role in which they try to anticipate the actions and desires of their seniors. Asserting that 'silence is a communicative act rather than a mere void in communicational space' (Lebra 1987, p. 343), Lebra proposes a fourfold significance of silence in Japanese communication, namely: sincerity and truthfulness, social discretion, embarrassment in articulating true feelings and the expression of defiance and hostility. Even so, much of what has been written about silence in Japan emanates from the nihonjinron canon of literature (see Befu 2001; Dale 1986) and is not based on reliable, empirical research. It therefore needs to be approached with a certain amount of caution, particularly where arguments for a simplistic binary between a silent, homogenous Japan and a talkative, individualistic 'West' are presented. To avoid such essentialism, we recommend the wise counsel of Nakane (2007, p. 23) who advises, 'there is a need to identify the nature of silence in communication in Japan in more specific terms: how are talk and silence distributed, and in what kind of contexts? Silence needs to be examined by identifying its forms, meanings and functions in context'.

\section{Silence in education}

In second language education contexts, silence in the form of a lack of oral participation during learning tasks is seen as a major problem by many educators. This is because there now exists a large, well-established body of research which suggests that output and interaction in the target language 
significantly aids second language development (de Bot 1996; Ellis 1999; Izumi 2003; Long 1996; Swain 2005). Student talk also fulfils an important social function within classrooms as it facilitates cooperation and promotes good interpersonal and group dynamics. In a large, multi-site investigation into the silent behaviour of over 900 Japanese learners of English who were studying within a higher education context, King (2013a, b) discovered that over the course of $48 \mathrm{~h}$ of structured classroom observation, students were responsible for less than one per cent of initiated talk, while over a fifth of observed class time was characterised by silence during which neither staff nor students spoke. King found that silence had multiple forms and functions within Japanese university classrooms and its causes were manifold and interrelated, with inhibition and socio-psychological factors proving particularly influential (see also King 2014). Nakane (2007) also investigated the silent behaviour of Japanese learners but her research focused on the seminar interactions of sojourners attending mainstream courses at a university in Australia. She suggests Japanese students are perceived as and are indeed likely to be non-vocal when compared to their Australian counterparts. Through careful analysis of a series of seminar interactions, Nakane found the reasons behind her participants' silences to be varied and complex, and that the specific classroom context in which a learning interaction took place proved to be a key factor in shaping participants' silent behaviour. Part of the challenge for some of these learners was that they were having to interact in learning situations using a second language and deficiencies in their English ability meant they required relatively long silent pauses in which to decode utterances and form appropriate responses.

While it is true that a lack of oral participation can inhibit a learner's second language development and prolonged silent pausing may cause misunderstandings in some crosscultural learning contexts, we should be cautious about assigning a purely negative connotation to student silence. Using a questionnaire methodology, Jaworski and Sachdev (1998) examined the beliefs and attitudes of Welsh secondary pupils to uncover how they valued silence within their classrooms. Interestingly, Jaworski and Sachdev's findings suggest that the students who were surveyed viewed their own silence in a positive manner and considered it to be 'a facilitative device enabling students to gain access, organise and absorb new material' (Jaworski and Sachdev 1998, p. 286). Thus the pupils believed that by refraining from talk in the classroom, they could improve the efficacy of their learning. Other studies also point towards the potential cognitive benefits of eschewing talk in the classroom. Drawing in part on her own experiences as a teacher, Reda (2009) analysed silence within American university composition classes and investigated how so-called quiet students within these classes viewed silence in learning situations. Framing silence in terms of a form of action, like the participants in Jaworski and Sachdev's study, Reda also sees the absence of talk as an opportunity for learning:

Rather than seeing silence as requiring the antidote of speech, I might more fruitfully see it as a productive disruption of expectations. As my students' stories suggest, it is possible to understand those silences not as signifying tension but as a space where work is being done. (2009, p. 169)

A similar notion of silence being used to facilitate learning is seen in Tatar's (2005) study of Turkish overseas students in the United States and Liu's (2002) examination of three Chinese sojourners attending an American university. In both these investigations, silence is culturally framed and seen as a mark of respect for the teacher. The trouble with employing silence as a politeness strategy (Sifianou 1997) though is that its inherent ambiguity means it is prone to misinterpretation, particularly within cross-cultural interaction contexts.

Finally, wait time is a construct closely related to classroom silence which also has positive implications for student learning. Defined as the silent duration between a teacher elicitation and student response, research suggests that by extending their silent wait time after solicits, teachers can improve the quality of classroom discourse and combat student non-responsiveness (Rowe 1986; Shrum 1985). In a recent mixed methods investigation into instances of wait time within a UK university second language classroom, Smith and King (2017) discovered that wait time played an intricate role in shaping classroom discourse patterns, with extended wait times of more than $2 \mathrm{~s}$ in length working to temporarily shift discourse out of a rigid Initiation Response Feedback (IRF) pattern (see Sinclair and Coulthard 1975) into a new, more student-driven phase. In contrast to this, Ingram and Elliot (2014), researching within secondary mathematics classrooms, found that outside of the IRF pattern, extending wait time may work against student self-selection as it reinforces the teacher's control over classroom discourse and may hinder more naturally flowing interactions.

\section{Research objectives}

The above review of literature demonstrates a need for empirical, cross-cultural research which measures, in a contextually valid manner, both silence and higher education students' reactions to silence. This study was therefore driven by the following research questions: 
1. How does the behaviour of an intact class of Japanese students compare to that of their British counterparts in terms of the length of silence they can tolerate during a one-to-one tutorial with their instructor?

2. Is there a relationship between the length of silence experienced by students during an encounter with their instructor and the level of discomfort they self-report feeling?

3. How do these two samples of students compare in terms of their mental reactions to silence during a tutorial meeting?

Definition of terms: Length of silence refers to the number of seconds measured from a set point in the tutorial during which neither the participating student nor the instructor produced an audible utterance. Level of discomfort relates to how at ease participants felt during the silence measured on a self-report semantic differential scale from one (most comfortable) to six (most uncomfortable). Mental reactions refer to the psychological responses students had to the silence in the form of their concurrent cognitions and self-talk.

\section{Method}

\section{Participants}

Great care had to be taken when selecting participants for the study so that any comparisons made between the Japanese and UK samples could be meaningful. Along with the context of an interaction, the level of familiarity between two people has significant potential to influence how tolerant they are to instances of silence when they transpire (e.g. think of the silence occurring between two strangers in a lift, compared to that between two slight acquaintances). This therefore meant that both groups of participants had to have an equal level of familiarity with the instructor who instigated a period of silence during the study's individual data collection encounters. The lead author's professional transition from an assistant professor teaching English for Academic Purposes at a large, foreign languages-orientated university in Japan to an applied linguistics instructor at a well-established UK institution provided a unique opportunity to achieve this parity. Both comparison groups were made up of first-year undergraduate students studying for a Bachelor degree in English who were nearing the end of a semester's instruction under the lead author's tutelage in their home countries. Whereas the UK students' course involved both language and literature elements, the Japanese group's studies centred primarily on English as a foreign language. This latter group had an institutional TOEFL score range between 437 and 510, making them intermediate level learners of English. The UK group $(n=15)$ was made up of 12 females and 3 males, all UK nationals, and their ages ranged from between 18 and 21 years old. The Japanese students $(n=20)$ had a similar sex and age profile, consisting of 15 females and 5 males who were all aged between 18 and 20. Participation was on a voluntary basis and students were assured that their performance in the experiment, or indeed a decision not to take part in the research at all, would have no bearing on their course grade. Following assurances of participant anonymity and data confidentiality, all members of the two intact classes approached agreed to take part in the study. Rather than using names, each participant received a code beginning with either an $\mathrm{E}$ (UK group) or $\mathrm{J}$ (Japan group), followed by a number and then $\mathrm{M}$ (male) or $\mathrm{F}$ (female). For example, E01F was the first student from the UK class and was female.

\section{Procedures}

A mixed methods, quasi-experimental design was employed to measure the length of silent pause which individual students from the samples in Japan and the UK were able to tolerate during a one-to-one staged encounter with their instructor. Students from both groups were familiar with short one-to-one tutorials as a way of gaining individual attention from instructors and receiving feedback on their learning, but this encounter was the first tutorial they had attended for their English class. It was 'staged' in the sense that they knew the tutorial would involve some form of data collection and was an extra, non-compulsory element of the course but in order to ensure natural behaviour they were not forewarned about the exact nature of the experiment. During this videotaped encounter, which took the form of a meeting in the instructor's office, the instructor refrained from speech and all overt non-verbal communication (adopting a neutral facial expression, gaze direction, posture and so on) from a set point in the meeting. The student participant's reaction to the period of silence which ensued was examined in detail using a non-verbal coding scheme (Allen and Honeycutt 1997; Gregersen 2005) and their length of silence tolerance was measured precisely using a digital stopwatch accurate to one hundredth of a second. Timings were double-checked by a research assistant. To code non-verbal behaviour, the lead researcher repeatedly viewed recordings of each tutorial to identify whether students had displayed non-verbal cues of anxiety through self-touching behaviours, bodily tension and position, gaze aversion and so on. To ensure reliability, a panel of four research assistants also assessed the recordings and any discrepancies in coding were discussed and agreed upon. In addition to quantitative data focusing on the nature of silent pause lengths, the study garnered qualitative data from retrospective interviews examining what participants were actually thinking and feeling whilst the silent encounter was in progress. Thus, it was possible to access students' 
private, inner self-talk (see Wang et al. 2017). Participants were also asked to self-report their comfort/discomfort during the silence by indicating on a six-point semantic differential scale how they had felt.

The contextual features of an interaction may significantly influence both the production and interpretation of any silences occurring within it (King 2015; Saville-Troike 1985). Such features relate not only to the interpersonal relationship between interlocutors, but also to the characteristics of the immediate setting. Thus, in addition to a sampling strategy which ensured a shared level of intimacy with the instructor across the two student groups, measures were employed to ensure that all participants were exposed to a standardised tutorial experience. After some brief small talk upon entering the tutorial room, each participant was asked to sit directly opposite the instructor who placed himself behind a desk at a distance of approximately $1.5 \mathrm{~m}$ away. Once any initial small talk had come to a natural conclusion and the moment both parties became seated, the instructor began the experiment proper by embarking upon a period of silence during which he avoided displaying any kinesic signals which might have been interpreted as a solicit or prompt to speak (e.g. direct eye contact, forward leaning body posture, positive facial expressions such as smiling). So as to ensure a natural reaction to the silence, prior to the data collection sessions participants were not informed about the specific topic under investigation. Instead they were told the research would focus on an aspect of staff-student interaction during tutorial sessions and were reassured as to the voluntary nature of the study, the maintenance of their anonymity and the confidentiality of any data collected. Interactions were video recorded with the participants' consent and although they were aware of the recorder, every effort was made to make it as unobtrusive as possible. Reactivity was therefore kept to an absolute minimum and this was reflected by the fact that in the post-silence interviews nobody referred to the presence of the recording equipment.

\section{Results and discussion}

\section{Length of silence and feeling of discomfort}

The quantitative data that the study produced centre primarily on two variables: the length of silence that students were able to tolerate before they spoke (measured in seconds using a digital stopwatch) and their self-reported feeling of discomfort during this period, as rated on a 6-point semantic differential scale. One UK participant (E01F) whose length of silence tolerance deviated more than 3SD was excluded from the quantitative analysis in order to avoid bias in the study's statistical results. Even so, this student's response to the experiment was so intriguing that we do provide some discussion of her performance later on in the paper. Reflecting the scourge of silence in the modern university classroom, a further UK participant's data (E16F) had to be discarded entirely from the study due to the fact that her mobile telephone rang during the experiment. This left a total number of participants of 34 in the quantitative phase of the study. Descriptive statistics for the whole sample revealed the standard deviation in the length of silence tolerated was quite high (35.38) and the kurtosis (the degree of distribution) was also a relatively high positive score (5.38) due to a small number of participants who were able to remain silent for much longer than their counterparts. The relatively small negative skewness value for feeling of discomfort $(-0.75)$ stems from the fact that participants' responses tended to gather within a narrow range around points 4-6 on the semantic differential scale. Figure 1 presents a scatterplot of the distribution of silence length and level of discomfort produced by the 34 participants in the study.

The scatterplot suggests that short periods of silence can be just as discomforting for students as longer silences (cf. Poyatos 2002). To confirm this, we performed a correlational analysis using Pearson's coefficient to examine whether there was correlation between the length of silence tolerated and level of discomfort experienced. The fact that the coefficient was not significant suggests that longer periods of silence did not necessarily induce a greater feeling

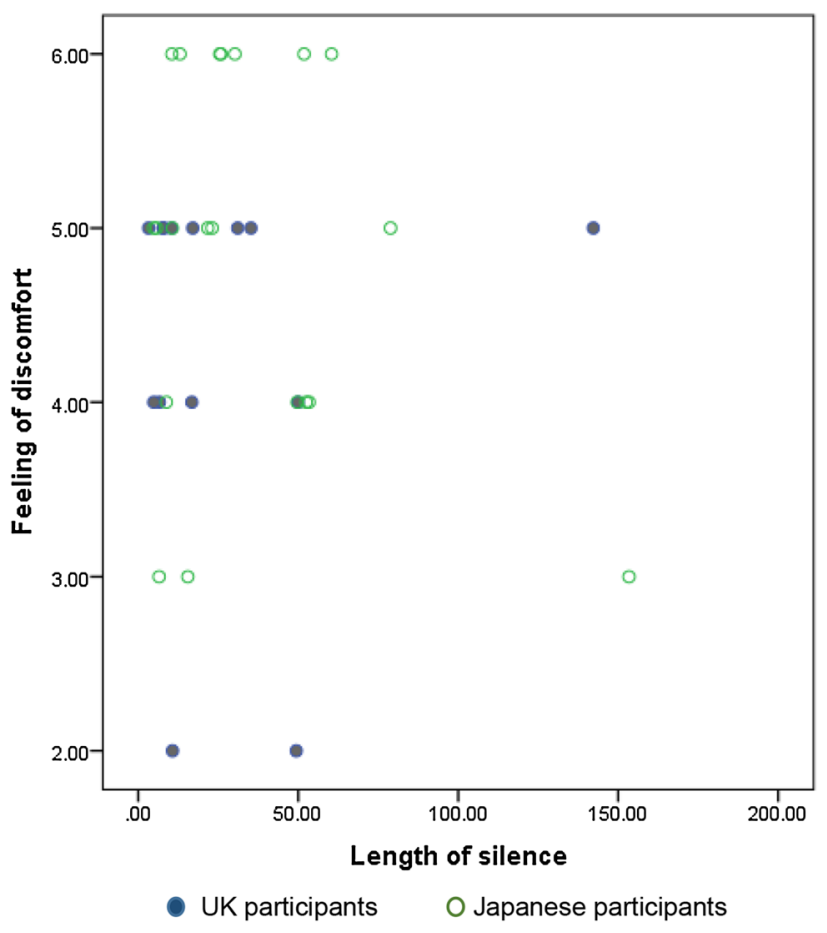

Fig. 1 Scatterplot showing of length of silence in relation to feeling of discomfort 
of discomfort amongst students in the sample $(r=-.107$; $p<.546 ; n=34)$.

Finally, we wanted to discover whether the two class groups differed in how long they could tolerate an enforced period of silence and whether one group felt more uncomfortable during this silence than the other. Taking into account distributions were not normal, we administered a Mann-Whitney $U$ test to examine whether there were any differences in the quantitative data generated by the Japanese and UK groups. Table 1 shows that although the Japanese group were able on average to tolerate silence for slightly more than $7 \mathrm{~s}$ longer than the UK group, we cannot really consider this to be a significant difference. Similarly, no significant difference was found in the levels of discomfort students experienced. The level of discomfort that both sets of students reported feeling during the silence was strikingly similar with a mean average of 4 on the scale of 6 .

These findings reveal similarities rather than differences in how the two groups responded to the experiment and are surprising considering what the literature (e.g. Ishii and Bruneau 1994; Lebra 1987; Yamada 1997) has to say about the relative prevalence of silence and positive attitudes towards non-vocalisation displayed within Japanese discourse communities when compared to Anglophone contexts. Even so, these quantitative results only tell part of the story of how of the students reacted to their instructor's silence and in order to gain a more nuanced understanding of their behaviour we must now turn our attention to the study's qualitative data.

\section{Situational silence anxiety}

After each silent episode ended, participants were interviewed about their internal reaction to their instructor's absence of talk and were asked to put into words any thoughts or feelings they had experienced during the silence. To aid the externalisation of their thoughts, the Japanese participants were encouraged to provide responses in their first language. We employed a grounded theory-based approach (Hadley 2017; Strauss and Corbin 1998) to the analysis of these data in which themes arose from the students' accounts rather than being imposed upon them. In reality, the open then axial coding we engaged in did not produce a wide variety of themes because participants' testimony from both the
UK and Japan groups centred around the feelings of anxiety, nervousness and confusion that they felt during the encounter. Coding of both groups' non-verbal affect displays (Allen and Honeycutt 1997; Gregersen 2005) provided further evidence of their anxiety and this manifested itself through such behaviours as self-touching, postural rigidity, closed body positions and gaze aversion. Overall, $73.33 \%$ of UK students and $80 \%$ of Japanese students displayed non-verbal cues of anxiety during the encounter.

Rather than using the term 'communication apprehension', we believe a better conceptualisation of the anxiety the participants felt would be situational silence anxiety. We define this construct as the apprehension or negative emotional reaction experienced during a situated encounter in which there is an expectation of talk but no talk occurs. This anxiety was illustrated well by the account of Japanese student J14F, who managed to tolerate a silence of just over $50 \mathrm{~s}$, stiff backed and with a forced smile throughout. She rated her level of discomfort with a maximum score of 6 . Describing her feelings during the encounter, she explained, "I felt anxious. Should I speak or should I wait? I knew it was part of the experiment but didn't know what to do and became worried. It was an unbearable length of silence". It was not only students who had tolerated a relatively long silence who provided an account of their unease. For example, UK undergraduate E14F was only able to tolerate a silence of just $2.37 \mathrm{~s}$ duration. Even so, according to the participant, this short pause made her feel "quite awkward and a little bit confused about what I was supposed to be doing. I chose to break the silence by saying 'Hi'. Then I felt much better". Her account appears to back up the study's quantitative results which found no correlation between length of silence and degree of discomfort amongst participants.

In addition to displaying unconscious non-verbal cues of anxiety during silent episodes, in the interviews afterwards a number of students referred to their own non-verbal behaviour which was consistent with feeling anxious. This was especially true regarding gaze direction. For example, E05F revealed, "I felt very awkward...I found myself looking around the room to try to distract myself-you feel kind of embarrassed. I couldn't really stand the silence so I tried to laugh it off". While E06F explained that she felt, "Uncomfortable, confused, waiting for something to happen. I wasn't
Table 1 Comparing the Japanese and UK groups' silence length and feeling of discomfort with Mann-Whitney U test

\begin{tabular}{lllllrrrr}
\hline Group & & $n$ & Min & Max & Mean & $\begin{array}{l}\text { Standard } \\
\text { deviation }\end{array}$ & $\begin{array}{l}\text { Standard } \\
\text { error of } \\
\text { mean }\end{array}$ & $\begin{array}{l}U \text { value (two- } \\
\text { way probabil- } \\
\text { ity) }\end{array}$ \\
\hline Length of silence & UK & 14 & 3.22 & 142.22 & 28.07 & 36.51 & 9.76 & 107.500 \\
& Japan & 20 & 4.85 & 153.89 & 35.09 & 35.22 & 7.88 & .255 \\
Feeling of discomfort & UK & 14 & 2 & 5 & 4.29 & 1.07 & .29 & 100.000 \\
& Japan & 20 & 3 & 6 & 4.85 & 1.09 & .24 & .142 \\
\hline
\end{tabular}


sure how to act, where to look, etc. Felt like there needed to be talking to avoid the awkward atmosphere". Both of these students sat with closed body positions and engaged in what Argyle and Cook (1976) term environmental scanning during which they tried to avoid looking at the tutor and instead followed static objects within their immediate environment as a way of concealing emotion or relieving anxiety (see also Perkins et al. 2012). Studies within the field of intercultural communication have tended to emphasise that in comparison to other cultures, the traditional Japanese notion is that prolonged eye contact with a superior may be interpreted as a threat or sign of rudeness (McDaniel 2003) and is therefore something to be avoided. Harumi's (1999) investigation of Japanese students' in-class silences at a British university revealed that these learners did tend to avert their gaze from their teacher during silences, while their British counterparts did not. In contrast, in the current study we found that participants from both groups engaged in some degree of gaze aversion and environmental scanning during silent episodes and we consider this to be further evidence of the similarities rather than differences in how the Japanese and UK students in the sample responded to their instructor's silence.

\section{Status inequality and student silence}

Implicit within all staff-student interactions is a disparity in status. Interpersonal power differences can help shape whether an individual decides to speak or not, with those in a subordinate position being more likely to remain silent (Braithwaite 1990; Gilmore 1985; King 2013a). With Japan's particularistic, rather than universalistic orientation towards social relationships and its preoccupation with the maintenance of face during interpersonal exchanges (see Akasu and Asao 1993), we would have expected the study's Japanese participants to have referred to this issue during interviews. However, in the end it was two UK participants who ended up addressing the issue directly. E15 M, who had a discomfort rating of 5 and had ended his 17-s silence with the words "Do I lose if I talk?" described how he had felt, "slightly intimidated by the instructor as whilst I am comfortable with him, he is a figure of authority and the figure in the tutorial who knew what was happening". Thus the already present power disparity between E15 M and his instructor appears to have been exacerbated by the ambiguous and out-of-the-ordinary nature of the tutorial encounter. Another UK student, E07F further emphasised this point when she stated that the tutorial felt, "strange because it was a teacher/student situation where usually I would expect to be talked at". Previous research (e.g. Forgas 1978) has demonstrated that, even without staff members behaving in an unexpected manner, students already perceive tutorials in terms of highly anxious social situations.
Testimony from the Japanese participants referred to status inequality in a more oblique way, with a number of students relating how they became concerned during the experiment that they had done something to displease the instructor and were in trouble. J12F, who remained silent for half a minute and rated her discomfort level as 6, stated, "I became very anxious about whether the instructor was angry. I thought maybe he's angry about the way I came into the room. I felt more and more nervous and became blank as I didn't know what to do". In a similar vein, J07F recounted, "As the instructor didn't say anything and also didn't change his facial expression, I thought I might have done something wrong", while J13F explained, "Because the instructor was silent, I wondered if I'd done something wrong. I giggled to escape the situation. To be honest, I was absolutely panicking!" What emerges in these accounts is the inherent ambiguity of silence and the students' anxious struggle to try and interpret its meaning. Rather than being communicative blanks in which nothing of importance happens, periods of silence may actually be rich in illocutionary force and full of meaning (Bruneau 1973; Ephratt 2008; Jaworski 1993; King 2013a; Saville-Troike 1985). What makes the situation even more problematic for these students is that the inherent ambiguity of silence tends to be exacerbated when it occurs within an intercultural context in which interlocutors lack a common background and do not share implicit assumptions about the messages which silence may carry.

\section{An active state of silence}

Linked to the idea that silences which occur during educational encounters may be alive with meaning is the notion that they also signify periods of intense cognitive activity for many learners. Particularly within East Asian education contexts, silence is often thought of as denoting passivity and this feeds into the cultural stereotype of the silent, submissive Asian learner who relies heavily on rote learning (cf. Cheng 2000; Kember and Gow 1991; Littlewood 2000). The current study's interview data challenge this idea and reveal how for students from both national groups the silence they endured was actually a period of intense mental activity. For example, J17F, whose silence was the longest amongst the Japanese sample at just over two and a half minutes, revealed that during the encounter, "I was thinking about what the instructor was thinking. Being silent made me feel anxious and unpleasant. I wondered whether it'd be better for me to say something. Anyway, I felt very uneasy". In a similar vein, J20F explained that her thoughts during the tutorial centred on the question of, "What is the teacher thinking?" as she tried to work out the most appropriate way to navigate her $49 \mathrm{~s}$ of silence. These findings complement those of Nakane's (2007) investigation into the silences of Japanese sojourners at an Australian university. Nakane 
found that many of her subjects required an extended time for cognitive processing during learning situations in order to organise their thoughts and come up with an appropriate response and this period of mental activity contributed to their silent behaviour. Even though the tutorial did not represent a foreign language intercultural encounter for the UK sample, we can still detect similarities in how they responded in an active cognitive way to silence. This is illustrated by E09F who described the mental struggle which she engaged in during nearly two and a half minutes of silence and recounted her thoughts thus, "Felt very awkward... Thoughts about what to do. Debate in head about whether to ask about it or not". E10F also made reference to cognitive processing during the recall interview, relating how she felt "like I'd missed out on something that should have been said and was trying to play mental catch up". While the testimony provided by the two groups points towards a similarity in how they responded to the absence of talk in terms of being mentally active, they do differ in terms of the UK participants lacking any direct reference of trying to reach an empathetic understanding of the instructor's communicative behaviour.

\section{The case of E01F and her high tolerance of silence}

It is at this point that we would like to turn our attention to the case of UK undergraduate E01F. This 19-year-old student was able to tolerate the longest silence of all the participants in the study and lasted a surprising $11 \mathrm{~min} 13.66 \mathrm{~s}$ without resorting to talk. As was stated earlier, her silence was so long in comparison to other students in the sample that we were forced to discard her quantitative results in order to avoid bias in the study's descriptive statistical data. Even so, her behaviour during the experiment and her subsequent commentary do raise some interesting points about student silence that are worth examining in more depth. After E01F's silent marathon had concluded, she explained:

I felt that I was obliged to remain silent until told otherwise. At first I felt intimidated and uncertain, but quickly felt relaxed and detached. I wondered at some points if the instructor wanted me to break the silence, but thought it was my decision. My mind wandered to other topics. At many points I was simply intrigued about the purpose of this exercise.

What is apparent from this account is the dynamic properties of the silence as the tutorial progressed and the participant's affective response to it. Like so many other students in the study, E01F was clearly anxious at the beginning of the encounter and her references to feeling intimidated and obliged to refrain from talk point towards an initial consciousness of the status disparities that the interaction with her instructor entailed. However, as the silence extended, her feelings of discomfort lessened, leading to a detachment in which she appears to have felt quite at ease. Coding of her non-verbal behaviour during the experiment appears to back this up. Sat with a closed body position and initially blushing, E01F began the silence with a series of glances towards the instructor which were accompanied by brief nervous smiles. As time wore on, her smiling lessened and she began to engage in environmental scanning before eventually casting her gaze downwards towards the desk in front of her for long intervals. Although she did hold a closed body position during the experiment, her posture remained relaxed throughout, particularly from $5 \mathrm{~min}$ into the silence. Even though E01F eventually rated her level of discomfort at only 3 on the scale of 6 , a single score on the differential scale cannot really capture evidence of dynamic change in how a participant feels during a prolonged silence.

It is not only a person's affective response to a protracted silence which may change over time, the very meaning of the silence can transform as interactants engage in the ongoing subjective interpretation of the ambiguous, implicit messages which silence carries and try to work out why the silence may have occurred in the first place. In the case of E01F's tutorial, the absence of talk seemed to take on a phatic function (see Jaworski 2000; Tannen 1985) as tutor and student shared in the silence and the expectation of talk diminished. What made E01F's tolerance of silence all the more unexpected though was the way in which she usually conducted herself in class. Scrupulously polite and always fully engaged with each lesson's content, E01F was perhaps the most orally active member of the UK group and could often be relied upon to provide responses when open-class solicits from the instructor went unanswered. In a learning context which encouraged dialogic learning (Mercer 2003; see also Otaka 2017) and valued active oral participation by students, she was highly literate in what Anstey (2003) terms the rules of engagement for effective classroom discourse. The reference in E01F's testimony to her belief that it was her decision whether to break the silence or not is significant because it implies she had concluded her own rules of engagement for the tutorial and these saw her appropriate power over who could initiate talk during the encounter.

\section{Conclusion and pedagogical implications}

By employing a quasi-experimental mixed methods methodology which paid close attention to the control of contextual variables, this study has been able to investigate the tolerance of silence by individuals from two intact classes of English major undergraduates, one from Japan and one from the UK, during a staged tutorial encounter with their instructor. Our findings point towards similarities rather than differences in how students from the two groups responded 
to an absence of talk during one-to-one tutorials. Hovering around the half minute mark, the Japanese and the UK groups displayed a mean average length of tolerance of silence that was within just $7 \mathrm{~s}$ of each other. A comparison of the self-reported level of discomfort that students experienced during these silences showed striking similarities, with the two groups being separated by a mean average score of just 0.56 on a semantic differential scale of 1-6. Self-reported feelings of discomfort during the silence were relatively high for both Japanese and UK participants, but length of silence was not found to be correlated with degree of discomfort. Qualitative data from post-silence interviews suggest that the dominant feeling experienced by both UK and Japanese participants was one of anxiety. Rather than communication apprehension or foreign language anxiety (in the case of the Japanese students), we propose a more appropriate term for what participants experienced in this study to be situational silence anxiety, which we define as being the apprehension experienced during a situated encounter in which, despite there being an expectation of talk, an absence of talk occurs. The study's qualitative data further showed that silence for both groups of learners represented a period of intense cognitive activity, with Japanese participants in particular attempting to engage in empathetic understanding of their instructor's silence.

The need to ensure parity in participants' level of familiarity with the instructor who instigated silent episodes during the data collection sessions meant that the study's sample was rather limited in size and thus we are not able to generalise the results to a wider population. Even so, the current research does suggest a number of pedagogical implications. We suggest that educators reflect on their own use of silence within their professional practice and try to gain an awareness of the implicit beliefs and assumptions which underpin their approach to oral participation within the educational context they operate in. In particular, educators should be attentive to their own use of silent wait time after posing questions or solicits to learners and be prepared to extend this time if the situation warrants it. The study showed that learners from both national groups became markedly anxious when there was an expectation of talk but the talk did not materialise. While a small amount of facilitative anxiety can be helpful for student performance (MacIntyre and Gardner 1994; Tobias 1986), excessive anxiety is inhibiting. We therefore suggest that in addition to creating a low-anxiety learning environment in which students have the confidence to share their thoughts and ideas, educators can help combat situational silence anxiety by making explicit the norms of interaction and turn-taking behaviours they expect in their classrooms or other learning settings. As there is a non-verbal dimension to anxiety, developing a familiarity with the non-verbal cues of anxious learners would also prove helpful. Finally, and perhaps most importantly, our study has demonstrated the folly of making assumptions about students' communicative behaviours based solely on the generalised sociocultural norms of discourse associated with their nation culture and that give no consideration to the specific contextual features of an interaction. While cultural differences in student behaviours patently do exist, for individual learners it is the interplay between their own learner-internal mental characteristics and the features of the immediate communicative setting which are likely to prove more influential in shaping both patterns of talk and patterns of silence.

Acknowledgements This work was supported in part by the Japan Foundation's Study Support Programme.

Open Access This article is distributed under the terms of the Creative Commons Attribution 4.0 International License (http://creativecommons.org/licenses/by/4.0/), which permits unrestricted use, distribution, and reproduction in any medium, provided you give appropriate credit to the original author(s) and the source, provide a link to the Creative Commons license, and indicate if changes were made.

\section{References}

Akasu, K., \& Asao, K. (1993). Sociolinguistic factors influencing communication in Japan and the United States. In W. B. Gudykunst (Ed.), Communication in Japan and the United States (pp. 88-121). New York: State University of New York Press.

Allen, T. H., \& Honeycutt, J. M. (1997). Planning, imagined interaction, and the nonverbal display of anxiety. Communication Research, 24(1), 64-82.

Anstey, M. E. (2003). Examining classrooms as sites of literate practice and literacy learning. In G. Bull \& M. E. Anstey (Eds.), The literacy lexicon (pp. 103-121). Frenchs Forest: Pearson Education.

Argyle, M., \& Cook, M. (1976). Gaze and mutual gaze. Cambridge: Cambridge University Press.

Befu, H. (2001). Hegemony of homogeneity: An anthropological analysis of Nihonjinron. Melbourne: Trans Pacific Press.

Braithwaite, C. A. (1990). Communicative silence: A cross-cultural study of Basso's hypothesis. In D. Carbaugh (Ed.), Cultural communication and intercultural contact (pp. 321-327). Hillsdale, NJ: Lawrence Erlbaum Associates.

Bruneau, T. J. (1973). Communicative silences: Forms and functions. The Journal of Communication, 23(1), 17-46.

Cheng, X. (2000). Asian students' reticence revisited. System, 28(3), 435-446.

Clancy, P. M. (1990). Acquiring communicative style in Japanese. In R. C. Scarcella, E. S. Anderson, \& S. D. Krashen (Eds.), Developing communicative competence in a second language (pp. 27-35). New York: Newbury House.

Cortazzi, M., \& Jin, L. (Eds.). (2013). Researching cultures of learning: International perspectives on language learning and education. Basingstoke: Palgrave Macmillan.

Dale, P. N. (1986). The myth of Japanese uniqueness. London: Routledge.

de Bot, K. (1996). The psycholinguistics of the Output Hypothesis. Language Learning, 46(3), 529-555.

Ellis, R. (1999). Learning a second language through interaction. Amsterdam: John Benjamins. 
Enninger, W. (1991). Focus on silence across cultures. Intercultural Communication Studies, 1(1), 1-37.

Ephratt, M. (2008). The functions of silence. Journal of Pragmatics, 40(11), 1909-1938.

Forgas, J. P. (1978). Social episodes and social structure in an academic setting: The social environment of an intact group. Journal of Experimental Social Psychology, 14(5), 434-438.

Frambach, J. M., Driessen, E. W., Beh, P., \& van der Vleuten, C. P. (2014). Quiet or questioning? Students' discussion behaviors in student-centered education across cultures. Studies in Higher Education, 39(6), 1001-1021.

Gilmore, P. (1985). Silence and sulking: Emotional displays in the classroom. In D. Tannen \& M. Saville-Troike (Eds.), Perspectives on silence (pp. 139-162). Norwood: Ablex.

Gregersen, T. (2005). Recognizing visual and auditory cues in the detection of foreign-language anxiety. TESOL Canada Journal, 28(2), 46-64.

Gudykunst, W. B., \& Nishida, T. (1993). Interpersonal and intergroup communication in Japan and the United States. In W. B. Gudykunst (Ed.), Communication in Japan and the United States (pp. 149-214). New York: State University of New York Press.

Hadley, G. (2017). Grounded theory in applied linguistics research. New York: Routledge.

Hammond, C. D. (2016). Internationalization, nationalism, and global competitiveness: A comparison of approaches to higher education in China and Japan. Asia Pacific Education Review, 17(4), 555-566.

Harumi, S. (1999). The use of silence by Japanese learners of English in cross-cultural communication and its pedagogical implications. Unpublished $\mathrm{PhD}$ dissertation, University of London.

Huang, F. (2014). Challenges for higher education and research: A perspective from Japan. Studies in Higher Education, 39(8), $1428-1438$.

Ingram, J., \& Elliott, V. (2014). Turn taking and 'wait time' in classroom interactions. Journal of Pragmatics, 62, 1-12.

Ishii, S., \& Bruneau, T. (1994). Silence and silences in cross-cultural perspective: Japan and the United States. In L. A. Samovar \& R. E. Porter (Eds.), Intercultural communication: A reader $(7$ th ed., pp. 246-251). Belmont: Thomson Wadsworth.

Izumi, S. (2003). Comprehension and production processes in second language learning: In search of the psycholinguistic rationale of the Output Hypothesis. Applied Linguistics, 24(2), 168-196.

Jaworski, A. (1993). The power of silence: Social and pragmatic perspectives. London: Sage.

Jaworski, A. (2000). Silence and small talk. In J. Coupland (Ed.), Small talk (pp. 110-132). Harlow: Pearson Education.

Jaworski, A., \& Sachdev, I. (1998). Beliefs about silence in the classroom. Language and Education, 12(4), 273-292.

Kember, D., \& Gow, L. (1991). A challenge to the anecdotal stereotype of the Asian student. Studies in Higher Education, 16(2), $117-128$.

King, J. (2013a). Silence in the second language classroom. Basingstoke: Palgrave Macmillan.

King, J. (2013b). Silence in the second language classrooms of Japanese universities. Applied Linguistics, 34(3), 325-343.

King, J. (2014). Fear of the true self: Social anxiety and the silent behaviour of Japanese learners of English. In K. Csizér \& M. Magid (Eds.), The impact of self-concept on language learning (pp. 232-249). Clevedon: Multilingual Matters.

King, J. (2015). Classroom silence and the dynamic interplay between context and the language learner: A stimulated recall study. In J. King (Ed.), The dynamic interplay between context and the language learner (pp. 127-150). Basingstoke: Palgrave Macmillan.

Kurzon, D. (1998). Discourse of silence. Amsterdam: John Benjamins.
Lebra, T. S. (1987). The cultural significance of silence in Japanese communication. Multilingua, 6(4), 343-357.

Littlewood, W. (2000). Do Asian students really want to listen and obey? ELT Journal, 54(1), 31-36.

Liu, J. (2002). Negotiating silence in American classrooms: Three Chinese cases. Language and Intercultural Communication, 2(1), $37-54$.

Long, M. H. (1996). The role of the linguistic environment in second language acquisition. In W. C. Ritchie \& T. K. Bhatia (Eds.), Handbook of language acquisition (Vol. 2: Second language acquisition) (pp. 413-468). New York: Academic Press.

MacIntyre, P. D., \& Gardner, R. C. (1994). The subtle effects of language learner anxiety on cognitive processing in the second language. Language Learning, 44(2), 283-305.

McDaniel, E. R. (2003). Japanese Nonverbal Communication: A reflection of cultural themes. In L. A. Samovar \& R. E. Porter (Eds.), Intercultural communication: A reader (10th ed., pp. 253-261). Belmont: Wadsworth.

Mercer, N. (2003). The educational value of dialogic talk in whole class dialogue. In New perspectives on spoken English in the classroom: Discussion papers (pp. 73-76). London: Qualifications and Curriculum Authority

Nakane, I. (2007). Silence in intercultural communication. Amsterdam: John Benjamins.

Otaka, K. (2017). From "employed work" to "associated work" in a diverse society: a challenge of social enterprise in creating a new paradigm of community development learning through works with multi-stakeholders. Asia Pacific Education Review, 18(2), $235-242$.

Perkins, A. M., Inchley-Mort, S. L., Pickering, A. D., Corr, P. J., \& Burgess, A. P. (2012). A facial expression for anxiety. Journal of Personality and Social Psychology, 102(5), 910-924.

Poyatos, F. (2002). Nonverbal communication across disciplines: Paralanguage, kinesics, silence, personal and environmental interaction (Vol. 2). Amsterdam: John Benjamins.

Reda, M. M. (2009). Between speaking and silence: A study of quiet students. Albany: State University of New York Press.

Rowe, M. B. (1986). Wait time: Slowing down may be a way of speeding up. Journal of Teacher Education, 37(1), 43-50.

Sacks, H., Schegloff, E., \& Jefferson, G. (1974). A simplest systematics for the organization of turn-taking in conversation. Language, 50(4), 696-735

Saville-Troike, M. (1985). The place of silence in an integrated theory of communication. In D. Tannen \& M. Saville-Troike (Eds.), Perspectives on silence (pp. 3-18). Norwood: Ablex.

Scollon, R., \& Scollon, S. W. (1981). Narrative, literacy, and face in interethnic communication. Norwood: Ablex.

Scollon, R., \& Scollon, S. W. (1990). Athabaskan-English Interethnic communication. In D. Carbaugh (Ed.), Cultural communication and intercultural contact (pp. 259-286). Hillsdale: Lawrence Erlbaum Associates.

Shrum, J. L. (1985). Wait-time and the use of target or native languages. Foreign Language Annals, 18(4), 305-314.

Sifianou, M. (1997). Silence and politeness. In A. Jaworski (Ed.), Silence: Interdisciplinary perspectives (pp. 63-84). Berlin: Mouton de Gruyter.

Sinclair, J. M., \& Coulthard, M. (1975). Towards an analysis of discourse. Oxford: Oxford University Press.

Smith, L., \& King, J. (2017). A dynamic systems approach to wait time in the second language classroom. System, 68, 1-14.

Strauss, A., \& Corbin, J. (1998). Basics of qualitative research: Techniques and procedures for developing grounded theory (2nd ed.). Thousand Oaks: Sage.

Swain, M. (2005). The output hypothesis: Theory and research. In E. Hinkel (Ed.), Handbook of research in second language teaching and learning (pp. 471-483). Mahwah: Lawrence Erlbaum. 
Tannen, D. (1984). Conversational style: Analysing talk among friends. Norwood: Ablex.

Tannen, D. (1985). Silence: Anything but. In D. Tannen \& M. SavilleTroike (Eds.), Perspectives on silence (pp. 93-111). Norwood: Ablex.

Tatar, S. (2005). Why keep silent? The classroom participation experiences of non-native-English-speaking students. Language and Intercultural Communication, 5(3-4), 284-293.

Tobias, S. (1986). Anxiety and cognitive processing of instruction. In R. Schuwartzer (Ed.), Self-related cognition in anxiety and motivation (pp. 35-54). Hillsdale: Erlbaum.
Wang, C., Shim, S. S., \& Wolters, C. A. (2017). Achievement goals, motivational self-talk, and academic engagement among Chinese students. Asia Pacific Education Review, 18(3), 295-307.

Watts, R. J. (1997). Silence and the acquisition of status in verbal interaction. In A. Jaworski (Ed.), Silence: Interdisciplinary perspectives (pp. 87-115). Berlin: Mouton de Gruyter.

Yamada, H. (1997). Different games, different rules: Why Americans and Japanese misunderstand each other. New York: Oxford University Press. 